\title{
Altered expression of itch-related mediators in the lower cervical spinal cord in mouse models of two types of chronic itch
}

\author{
BAO-WEN LIU, ZHI-XIAO LI, ZHI-GANG HE, QIAN WANG, CHENG LIU, \\ XIAN-WEI ZHANG, HUI YANG and HONG-BING XIANG \\ Department of Anesthesiology and Pain Medicine, Tongji Hospital, Tongji Medical College, \\ Huazhong University of Science and Technology, Wuhan, Hubei 430030, P.R. China
}

Received March 2, 2019; Accepted June 13, 2019

DOI: $10.3892 /$ ijmm.2019.4253

\begin{abstract}
In this study, we focused on several itch-related molecules and receptors in the spinal cord with the goal of clarifying the specific mediators that regulate itch sensation. We investigated the involvement of serotonin receptors, opioid receptors, glia cell markers and chemokines (ligands and receptors) in models of acetone/ether/water (AEW)- and diphenylcyclopropenone (DCP)-induced chronic itch. Using reverse transcription-quantitative polymerase chain reaction, we examined the expression profiles of these mediators in the lower cervical spinal cord (C5-8) of two models of chronic itch. We found that the gene expression levels of opioid receptor mu 1 (Oprm1), 5-hydroxytryptamine receptor 1A (Htrla) and 5-hydroxytryptamine receptor 6 (Htr6) were upregulated. Among the chemokines, the expression levels of $\mathrm{C}-\mathrm{C}$ motif chemokine ligand $(\mathrm{Ccl}) 21, \mathrm{Cxcl} 3$ and $\mathrm{Cxcl} 16$ and their receptors, Ccr7, Cxcr2 and Cxcr6, were simultaneously upregulated in the spinal cords of the mice in both models of chronic itch. By contrast, the expression levels of $\mathrm{Ccl} 2, \mathrm{Ccl} 3, \mathrm{Ccl} 4$ and $\mathrm{Ccl} 22$ were downregulated. These findings indicate that multiple mediators, such as chemokines in the spinal cord, are altered and may be central candidates in further research into the mechanisms involved in the development of chronic itch.
\end{abstract}

\section{Introduction}

An 'itch' was defined as 'an unpleasant sensation that elicits the desire or reflex to scratch' by Samuel Hafenreffer, almost 1,350 years ago (1). It is still difficult to treat pruritus, or chronic

Correspondence to: Professor Hui Yang or Dr Hong-Bing Xiang, Department of Anesthesiology and Pain Medicine, Tongji Hospital, Tongji Medical College, Huazhong University of Science and Technology, 1095 Jiefang Road, Wuhan, Hubei 430030, P.R. China E-mail: tjmzkyh@126.com

E-mail: xhbtj2004@163.com

Key words: chronic itch, dry skin, contact dermatitis, spinal cord, 5-hydroxytryptamine receptors, opioid receptors, glia marker, chemokines itchy skin, as its pathophysiological mechanisms remain elusive (2-5). Similar to many other diseases, itch manifests in two forms. Acute itch is relieved easily by scratching, while chronic itch, which is further categorized according to dermatological, systemic, neuropathic and psychogenic subtypes based on clinical relevance, remains a challenge to cure (6). Although Sun and Chen indicated gastrin-releasing peptide receptor (GRPR) as the first dedicated molecule that mediates pruritus, the itch pathogenesis remains unclear (7).

According to a number of studies, pruritus and pain are two fundamental sensory perceptions that share close associations in neural pathways (8-10). Although opioids, which affect the body by activating opioid receptors, such as the $\mu$-opioid receptor (MOP), $\delta$-opioid receptor (DOP), $\kappa$-opioid receptor (KOP) and nociceptin/orphanin FQ peptide receptor (NOP), are integral transmitters in pain pathways, it has been reported that they play important roles in the development and maintenance of chronic itch (11). The effect of opioid receptors on itch appears to be subtype-dependent. For example, activated MOP results in pruritus, whereas activated KOP suppresses itching. A previous study by Ahmadi et al revealed that endogenous opioid and gene expression levels of MOP were unaltered in brain areas of cholestasis-induced analgesia and pruritus in rats (12). Serotonin or 5-hydroxytryptamine (5-HT), which has been identified as a potent inducer of itching, is synthesized by enterochromaffin cells in the gastrointestinal tract and serotoninergic neurons in the central nervous system, although only a small percentage is synthesized by the latter (13-16). Depending on sequence homology and interrelated second messenger systems, serotonin receptors are classified into 7 groups (5-HT1-7) with 15 subtypes. 5-HT3 receptors are ligand-gated non-selective cation channels, while the other 5-HT receptors are G-protein coupled receptors $(17,18)$. As selective serotonin reuptake inhibitors have been increasingly used in the treatment of pruritus in the clinical setting, the anti-pruritic role of centrally released serotonin has been highlighted by numerous studies (19). The importance 5-HT in acute and chronic itch has been increasingly reported; however, the specific subtypes of 5-HT receptors that are involved in serotonergic itch signal transduction have not yet been fully investigated due to the complexity of the serotonergic system. Although the exact subtypes of 5-HT receptors involved in different mouse models of chronic itch have yet to be elucidated, these studies reflect the integral role of serotonergic 
signaling in chronic itch. Microglia and astrocytes have also been reported to promote chronic pain by producing related mediators, such as proinflammatory cytokines, growth factors, and chemokines that activate and sensitize nociceptive neurons in the spinal cord (20-23). Moreover, Shiratori-Hayashi et al indicated that astrocytes in the spinal cord played a dominate role in chronic itch by activating the signal transducer and activator of transcription 3 (STAT3) (24). Despite the prominent manifestation of the roles of glial cells in the genesis and maintenance of chronic pain, their effects on itching remain unclear.

Chemokines, which are generally of low molecular weight ranging from 7 to $15 \mathrm{kDa}$, have been classified into 4 subfamilies based on the number and location of cysteine residues at the $n$-terminus named CC, CXC, XC and CX3C (25). As chemoattractants, their main functions are to control the migration and residence of all immune cells in various immune responses (26). Although chemokines are well-known regulators of peripheral immune cell trafficking, several chemokines have been proven to be involved in chronic pain in the spinal cord $(27,28)$. In the central nervous system, chemokines have been reported to function in neuronal development, synaptic transmission and disease-associated neuroinflammation through a G-protein coupled receptor under both physiological and pathological conditions (29-31).

Chronic itch, which can result from immune dysfunction, is a common component of a number of inflammatory skin diseases, such as dry skin, atopic dermatitis, contact dermatitis and allergic contact dermatitis. The application of acetone/ether/water (AEW) weakens the water-retaining capacity of skin by breaking the cutaneous barrier function, leading to dry skin and severe pruritus (32). The dry skin model recapitulates the pathophysiological characteristics of chronic itch that are observed in human dermatitis, such as senile xerosis, atopic dermatitis, seasonal xerosis in winter, renal failure and cholestasis $(33,34)$. Diphenylcyclopropenone (DCP) is an immunotherapy agent for alopecia areata that typically induces eczematous skin, contact dermatitis and severe pruritic in patients. Treatment with DCP in both mice and rats often results in increased and persistent scratching behaviors $(35,36)$.

It is well-known that inflammatory mediators in the peripheral and central nervous systems can lead to pain and itch hypersensitivity by activating or sensitizing nociceptive and pruriceptive neurons directly (37). Given the remarkable function of related mediators in chronic itch, the investigation of whether the expression of these mediators is dysregulated in chronic itch conditions is integral. In this study, we investigated the gene expression of several related molecules and receptors that may represent novel candidate itch transducers in two types of chronic itch models. We report that the levels of multiple mediators, such as several 5-HT receptors and chemokines in the spinal cord were altered and may be significant candidates for investigating the transmission and development of chronic itch further.

\section{Materials and methods}

Animals and animal care. A total of 64 adult male C57BL/6J mice aged 8-10 weeks (weighing 20-25 g) were raised in the Animal Centre of Tongji Hospital (license no. 42000600018076). They were maintained in a vivarium (temperature, $22-24^{\circ} \mathrm{C}$; humidity, 50-60\%) with sufficient food and water and a $12 \mathrm{~h}$ light/12 h dark cycle. All experiments were performed under protocols approved by the Institutional Animal Care and Use Committee of Tongji Hospital, Huazhong University of Science and Technology (IRB ID:TJ-A0803).

Experimental design. It has been reported by numbers of researchers that AEW-induced dry skin itch and DCP-induced contact dermatitis can be successful established in C57BL/6J mice and that the pruritic behavior is stable (38-40). In addition, the present study was built upon our previous study (16). Therefore, we selected C57BL/6J mice for use in this study. Three sets of experiments were performed as follows: i) Experiment A: Mice were randomly assigned to 2 groups, namely the water group $(n=10)$ and the AEW group $(n=10)$. Pruritic behavior was measured. ii) Experiment B: Mice were divided into the acetone group $(n=10)$ and the DCP group $(n=10)$. Scratching behaviors were video-recorded. iii) Experiment C: Mice were randomly assigned to 3 groups, namely the naïve control group $(n=8)$, the AEW group $(n=8)$ and the DCP group $(n=8)$. After behavior testing was completed, C5-C8 tissue was prepared for reverse transcription-quantitative PCR (RT-qPCR).

$A E W$-induced model of chronic itch. Mice were shaved at the back of neck and randomly assigned to the AEW group $(n=10)$ and the control group $(n=10)$. The neck skin of the mice in the AEW group was painted with acetone and diethyl ether for $15 \mathrm{sec}(1: 1)$ followed by water for $30 \mathrm{sec}$ twice per day (9:00 and 16:00) for 8 days consecutively as previously described (32). The mice in the control group were painted with water for $45 \mathrm{sec}$. Spontaneous scratching was recorded on the day before applying AEW and on day 9, following the final AEW treatment.

DCP-induced chronic itch model. Mice were shaved at the back of neck and assigned to the DCP group $(n=10)$ and control group $(n=10)$. The neck skin of the mice in the DCP group was painted with $0.1 \mathrm{ml} 1 \%$ DCP (Shanghai Aladdin Biochem Technology Co., Ltd.) dissolved in acetone on day 1 and day 7 under conventional conditions (35). The neck skin of the mice in the control group was painted with $0.1 \mathrm{ml}$ acetone. According to our preliminary experiment results, scratching behaviors were video-recorded on the day before the DCP application and day 10 , following the final DCP treatment.

Behavioral test. From 3 days before the test, the mice were put in a plastic chamber $(9 \times 9 \times 13 \mathrm{~cm})$ for $30 \mathrm{~min}$ each day to acclimatize to the testing environment. Each time, the mice were allowed to acclimatize for $30 \mathrm{~min}$. The measuring cases were placed on a transparent glass, which was elevated by a metal floor; spontaneous itch behavior was video-recorded below the glass in the absence of any observer for $1 \mathrm{~h}$. As previously reported, a scratching bout is defined as lifting a hind paw towards the shaved region and returning the hind paw back to the floor or mouth for licking (36). The behavior videotapes were assessed in a blinded manner.

Tissue collection. After the behavioral testing was completed, the mice were placed in a 1 liter Plexiglass anesthetic induction 
Table I. Primer sequences used in RT-qPCR.

\begin{tabular}{|c|c|c|}
\hline Gene & Forward (5' to $\left.3^{\prime}\right)$ & Reverse (5' to $\left.3^{\prime}\right)$ \\
\hline Oprm1 & GCCCTCTATTCTATCGTGT & TAGTGGCTAAGGCATCTGC \\
\hline Oprk1 & TCTTCGTCTTTGCCTTTGT & GATTTCGGTCCTTCTCTCG \\
\hline Oprdl & CTGCGTGTTCCTCTTTGCC & GCTGCGGTCCTTCTCCTTG \\
\hline Oprll & CACAAGTGGAGGATGAAGA & ATGAAGGAAAAAAGGAAGA \\
\hline Htrla & TACTCCACTTTCGGCGCTTT & GGCTGACCATTCAGGCTCTT \\
\hline$H t r l b$ & TACACGGTCTACTCCACGGT & CGGTCTTGTTGGGTGTCTGT \\
\hline Htrld & GCTCTGGACAGATACTGGGC & AGTCGGACATCTCCTCGTGA \\
\hline Htrlf & CAACAGTTGAGCCTGCCACA & GCCAGCCCAGACAGAGTGAG \\
\hline$H t r 2 a$ & AACCCCATTCACCATAGCCG & CCGAAGACTGGGATTGGCAT \\
\hline$H t r 2 b$ & TGGATGGGTCTCACAGGGAT & AAAGGGGCACCACATAAGCA \\
\hline$H \operatorname{tr} 2 c$ & GCATAGCCGGTTCAATTCGC & TTGCTTTCGTCCCTCAGTCC \\
\hline$H t r 3 a$ & GACCATCTTCATTGTGCGGC & AGTGGTTTCCCATGGCTGAG \\
\hline$H t r 3 b$ & CCAGTTCCGGTCCATCAACA & CACGGCAAGGTAGATTCGGA \\
\hline Htr4 & GATGACCCCTCTACGCATCG & CCAGCCTTGCATTATGGGGA \\
\hline$H t r 5 a$ & TCTTCCTGTGGTTGGGCTATT & CCCTTGGCAGATGGATCTTGT \\
\hline$H t r 5 b$ & СTCCTATGCTGTCTTCTCCACC & CCACGAGTCTCCGCTTGTC \\
\hline Htr6 & GCATAGCTCAGGCCGTATGT & TCCCGCATGAAGAGGGGATA \\
\hline Htr7 & TTCTGCAACGTCTTCATCG & ATTCTGCCTCACGGGGTA \\
\hline$N p p b$ & GGCCTCACAAAAGAACACCC & CAGGCAGAGTCAGAAACTGGA \\
\hline Nprl & GGCTGTGAAACGTGTGAACC & GTCGGTACAAGCTCCCACAA \\
\hline Grp & TGGGCTGTGGGACACTTAAT & GCTTCTAGGAGGTCCAGCAAA \\
\hline$G r p r$ & GGGAAGACGGGAAATGCTGT & ATGTTGGTTCTGTCCCAGCC \\
\hline Gfap & TTGCTGGAGGGCGAAGAAAA & TGGTGAGCCTGTATTGGGAC \\
\hline Ibal & GCTTTTGGACTGCTGAAGGC & GTTTGGACGGCAGATCCTCA \\
\hline Map2 & АССТТССТССАТССТСССТС & TCCTGCTCTGCGAATTGGTT \\
\hline Ccll & TGCTGCTTGAACACCTTGAA & TTAGTTGAGGCGCAGCTTTCT \\
\hline Ccl2 & CCTGCTGCTACTCATTCACCA & ATTCCTTCTTGGGGTCAGCA \\
\hline Ccl3 & CCCAGCCAGGTGTCATTTTC & CAGGCATTCAGTTCCAGGTCA \\
\hline Ccl4 & CACCATGAAGCTCTGCGTGTC & GCAGGAAGTGGGAGGGTCAG \\
\hline Ccl5 & GTGCCCACGTCAAGGAGTAT & TTCTCTGGGTTGGCACACAC \\
\hline Ccl6 & TATCCTTGTGGCTGTCCTTGG & TACATGGGATCTGTGTGGCA \\
\hline Ccl7 & GATCTCTGCCACGCTTCTGT & ATAGCCTCCTCGACCCACTT \\
\hline Ccl8 & TCTACGCAGTGCTTCTTTGC & GCAGGTGACTGGAGCCTTAT \\
\hline Ccl9 & GCCCAGATCACACATGCAAC & AGGACAGGCAGCAATCTGAA \\
\hline Ccll1 & AGAGCTCCACAGCGCTTCTA & GGAAGTTGGGATGGAGCCTG \\
\hline Ccll2 & CAGTCCTCAGGTATTGGCTGG & GGACACTGGCTGCTTGTGAT \\
\hline Ccll9 & TTCACGCCACAGGAGGACA & TTCCGCATCATTAGCACCC \\
\hline Ccl2O & CCAGGCAGAAGCAAGCAACTAC & CGGCCATCTGTCTTGTGAAAC \\
\hline Ccl21 & TGGACCCAAGGCAGTGATG & CGGGATGGGACAGCCTAAAC \\
\hline Ccl22 & CTTGCTGTGGCAATTCAGACC & GAGGGTGACGGATGTAGTCC \\
\hline Ccl24 & TGAACTCTGAGCTGTGCCTGAC & TCTTATGGCCCTTCTTGGTGA \\
\hline Ccl25 & AGTGGAAGCTGCAACCTACG & GCACTCCTCACGCTTGTACT \\
\hline Ccl27 & TTTCCTTGGCTGCGAATGTG & CTGCTTGGGAGTGGCTGTCT \\
\hline Ccl28 & GCTGTGTGTGTGGCTTTTCAA & GGCTCTCATCCACTGCTTCA \\
\hline Cxcll & ACTTCCAGACTCGCCCAA & TTCCGACCTCCTGATAAACA \\
\hline Cxcl2 & CCCTAAAGAAACCTCGTGCC & TCAGAAATCGGGTGCCAG \\
\hline Cxcl3 & CCTACCAAGGGTTGATTTTGAGAC & AGTGGCTATGACTTCTGTCTGGGT \\
\hline Cxcl4 & GTGAGATTGGGTGAAGGGAT & TGAGGGTAAACGGGGAGAA \\
\hline Cxcl5 & CTCAGTCATAGCCGCAACG & GGGATAAGGGATGTGGGTAG \\
\hline Cxcl7 & TGTGCTGATGTGGAAGTGATG & TGACGATTCTCTTGACGCC \\
\hline Cxcl9 & CCTGGCAACAGAGAGTGACA & GCTTACCCAGGTCAGTGTCTAT \\
\hline Cxcl10 & GAGGTGCCTTCTTAGGTCATAC & GGAATAGACTCTGCTTTCACTTTG \\
\hline
\end{tabular}


Table I. Continued.

\begin{tabular}{|c|c|c|}
\hline Gene & Forward (5' to $\left.3^{\prime}\right)$ & Reverse (5' to $3^{\prime}$ ) \\
\hline Cxcl11 & GAAGGTCACAGCCATAGCCC & TTGTCGCAGCCGTTACTCG \\
\hline Cxcl12 & ACATTTGGGGATGCTCAGTA & CTAAGCCCTGGAAATCACAA \\
\hline Cxcl13 & ATCGGATTCAAGTTACGCC & GTTTGGTTCAGTTGGATTGC \\
\hline Cxcl14 & CAAAAGGCTTGCTAGGGATT & CACTTGATGAAGCGTTTGGT \\
\hline Cxcl15 & CTGTGGCTCTGGACAAGTATG & GAAATCAACTGTCTCCTCTGCTAA \\
\hline Cxcll6 & TTTGGAATGAGGAAAGGTAGG & GCAAAGGGCATTGTAAGGT \\
\hline Cxcl17 & TCATCTCCCTTGAGCCCCT & TGCTTGTGTAGACTTGGTAGGC \\
\hline Xcll & CCAAATGGGTGAAAGCAGCG & TCAGGGTTATCGCTGTGCTG \\
\hline Cx3cll & CTCACGAATCCCAGTGGCTT & TTTCTCCTTCGGGTCAGCAC \\
\hline Ccrl & CACTCACCGTACCTGTAGCC & GCAAATATCAGACGCACGGC \\
\hline Ccr2 & GCCATCATAAAGGAGCCATACC & ATGCCGTGGATGAACTGAGG \\
\hline Ccr3 & ATGGAGTAAAGTAGTCGCAGTGG & GCCATTCTACTTGTCTCTGGT \\
\hline Ccr4 & CATCTCGGATTTGCTGTTCGT & TGCCGCTGTAGAAGCCCAC \\
\hline Ccr5 & CCTAGCCAGAGGAGGTGAGACA & GCAGGGTGCTGACATACCATAA \\
\hline Ccr6 & GCATTTCCTGGGACTTGCTT & AGGTACTCCTGCCTCAGTGGTT \\
\hline Ccr 7 & TGTGATTTCTACAGCCCCCAG & AAAATGACAAGGAGAGCCACCA \\
\hline Ccr 8 & GAAACCTCAGAAGAAAGGCTCG & GCGGTGAAGAAATCAGGGTAG \\
\hline $\operatorname{Ccr} 9$ & GGAGGCTGGTCTGCATTATCTT & AAGGCTTGTGAGTTCTGTGGG \\
\hline Ccrlo & GGACCAAGCCCACAGAGCA & AGGGAGACACTGGGTTGGAAG \\
\hline Cxcrl & CAATGGCCGAGGCTGAATA & GAAGGGACACCAGTGCATAAAA \\
\hline Cxcr2 & TAGGTGTCCCACAGGTGAAAAG & AGAATAGAGGGCATGCCAGAG \\
\hline Cxcr3 & CCCAACCACAAGTGCCAAAG & TTCCAGAAGAAAGGCAAAGTCC \\
\hline Cxcr 4 & ACGGCTGTAGAGCGAGTGTTG & TGGGCAGGAAGATCCTATTGA \\
\hline Cxcr 5 & GGACATGGGCTCCATCACATAC & TCCCATCATACCCAGGAGGAA \\
\hline Cxcr6 & TGGCTCTTCAACAATTCCAGTG & ACCAGGGAGTTTCCTAGCAGTC \\
\hline Cxcr 7 & GAGGACACCCCACAAATCACT & TGCACATCCATGGTCTTGAGG \\
\hline Xcrl & CATGGGTTCTTGGCCTCAG & GTGTGAGGTTGTAGGGAGCC \\
\hline$C \times 3 c r 1$ & GTCACCATTAGTCTGGGCGT & CCCAGACACTCGTTGTCCTT \\
\hline Gapdh & GACAAAATGGTGAAGGTCGGT & GAGGTCAATGAAGGGGTCG \\
\hline
\end{tabular}

chamber. The induction chamber was filled with $4 \%$ isoflurane in $100 \%$ oxygen. In order to examine the loss of righting reflex, the chamber was tipped over. After losing their righting reflex, the mice were laid in abdominal position on a heating pad and maintained with $2 \%$ isoflurane in $100 \%$ oxygen via nose cone. After achieving surgical anesthetic depth, the treated skins at the back of neck were cut and collected. Subsequently, the mice were euthanized by rapid decapitation. The mouse heads were removed, and the spinal columns were opened to expose the cervical spinal cord. The cervical spinal cord was cut into 2 segments. The lower cervical segment of each spinal cord (C5-8) was collected in a RNase-free cryogenic vial and kept at $-80^{\circ} \mathrm{C}$ for subsequent analysis after freezing in liquid nitrogen.

$R T-q P C R$. Total RNA was extracted from the lower cervical spinal cords (C5-8) using the RNAiso Plus kit (Takara) according to the manufacturer's instructions (41). RNA purity and concentration were determined using Nano Drop Lite (Thermo Fisher Scientific). High quality samples containing $1 \mu \mathrm{g}$ of total RNA were reverse transcribed to synthesize cDNA using the
Prime Script RT Reagent kit (Takara). qPCR was performed on a LightCycler system (StepOne, Applied Biosystems) using SYBR Premix Ex Taq II (Takara). The total reaction volume was $20 \mu \mathrm{l}$, and reaction conditions were established according to manufacturer's protocol as follows: 1 cycle of denaturation at $95^{\circ} \mathrm{C}$ for $3 \mathrm{~min}$, followed by 40 cycles of denaturation at $95^{\circ} \mathrm{C}$ for $30 \mathrm{sec}$, annealing at $60^{\circ} \mathrm{C}$ for $20 \mathrm{sec}$, and extension at $72^{\circ} \mathrm{C}$ for $10 \mathrm{sec}$. Each reaction was concluded with a melting curve analysis to test the amplicon specificity by heating from 55 to $95^{\circ} \mathrm{C}$ in $0.5^{\circ} \mathrm{C}$ increments $/ 30 \mathrm{sec}$, with fluorescence recorded at each increment. The data was quantified using a comparative CT method with the formula for relative fold change $=2^{-\Delta \Delta c q}$ as previously described and compared with the housekeeping gene average (42). The experiments were performed in triplicate. The primers sequences used are listed Table I.

Histological analysis. The treated skin was collected to perform a histological examination. After the skin samples were fixed with $4 \%$ paraformaldehyde overnight and embedded with paraffin, the tissues were sectioned at $14 \mu \mathrm{m}$ using a cryostat and stained with hematoxylin and eosin (H\&E), as previously 
A

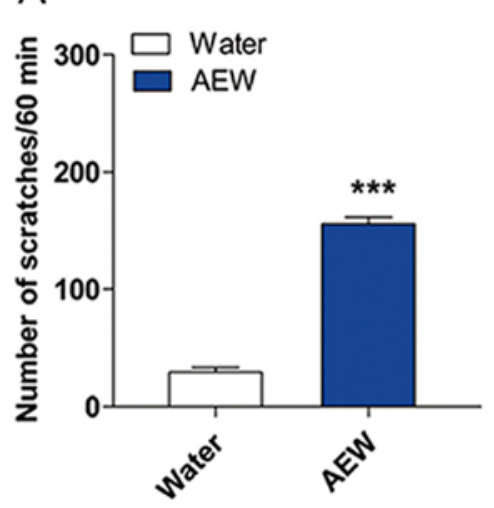

B

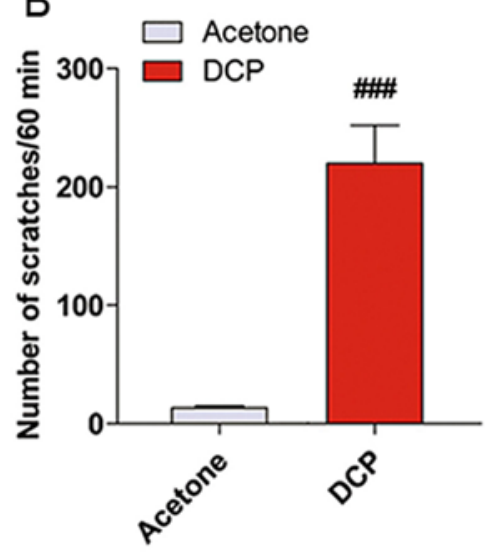

Figure 1. Scratching behaviors in the control group and treatment groups. (A) The back of the necks of mice were treated twice daily with AEW or water in dry-skin itch model. Scratching behaviors were observed on the day 9 after the final treatment. (B) The back of the necks of mice were treated with DCP or acetone on day 1 and day 7 in contact dermatitis itch model. Scratching behaviors were observed on the day 10. Each value represents the mean $\pm \mathrm{SEM}\left(\mathrm{n}=7-8\right.$ mice per group). ${ }^{* * * *} \mathrm{P}<0.001$ vs. the mice treated with water. ${ }^{\# \#} \mathrm{P}<0.001$ vs. the mice treated with acetone. AEW, acetone/ether/water; DCP, diphenylcyclopropenone.

described (32). The stained sections were observed and captured using a bright light microscope (Olympus). The thickness of the epidermal was determined by measuring the distance between the junction of dermal-epidermal and surface of the epidermal. Epidermal thickness was quantified by Image $\mathbf{J}$ software (National Institutes of Health, Bethesda, MD, USA).

Statistical analysis. All quantification data are expressed as the means \pm SEM, and error bars represented SEM. Behavioral tests were performed as well as the Student's t-test, measurements of epidermal thickness, and RT-qPCR analysis with one-way ANOVA and Dunn's post hoc test, both of which were performed using GraphPad Prism software (GraphPad Software, Inc.). $\mathrm{P}<0.05$ was considered to indicate a statistically significant difference.

\section{Results}

$A E W$ - and DCP-induced scratching behaviors in mice. The number of spontaneous scratching bouts (SSB) within $1 \mathrm{~h}$ between the model group and control group were assessed in a blinded manner. As shown in Fig. 1, the AEW-treated
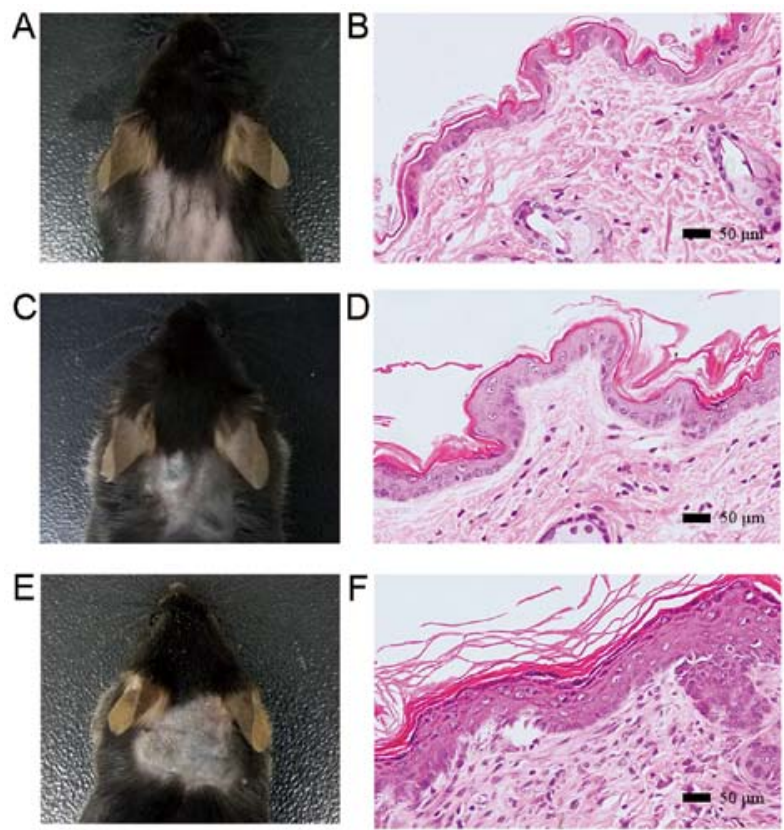

G

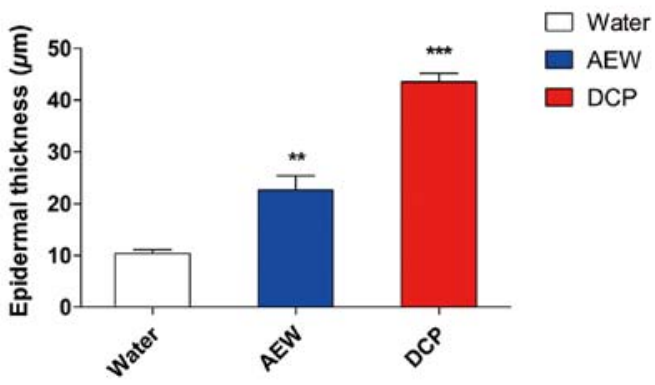

Figure 2. Hematoxylin and eosin (H\&E) staining of the mouse skin. (B, D and F) The images represent the H\&E-stained sections from the skins treated with (B) nothing, (D) AEW and (F) DCP. (A) A representative image of the skin from an untreated mouse. The skin was smooth and soft. (C) A representative image of the AEW application site from the AEW group. The skin was unsmooth and rough. (E) A representative image of the DCP application site from the DCP group. The skin manifested congestion and sclerosis and was accompanied by scratches and incrustation. (G) Epidermal thickness of the skin in two mouse models of chronic itch and naïve mice. There was apparent epidermal hyperplasia in the AEW and DCP groups compared with the untreated naïve group. Each value represents the mean \pm SEM ( $\mathrm{n}=3-5$ mice per group). ${ }^{* *} \mathrm{P}<0.01$ and ${ }^{* * *} \mathrm{P}<0.001$ vs. naïve mice. AEW, acetone/ether/water; DCP, diphenylcyclopropenone.

mice exhibited a significantly greater number of SSBs $(\mathrm{SSB}=155.5 \pm 6.009, \mathrm{n}=8, \mathrm{P}<0.001)$ at day 9 compared with the water-treated mice $(\mathrm{SSB}=29.38 \pm 3.923, \mathrm{n}=8)$. The number of SSBs in the DCP-treated mice (SSB=219.9 $\pm 32.31, \mathrm{n}=7$ ) exhibited an obvious difference between the acetone-treated mice at day $10(\mathrm{SSB}=13.29 \pm 1.599, \mathrm{n}=7, \mathrm{P}<0.001)$.

Histological observations of the skin. H\&E staining of skins of mice from the naïve, AEW and DCP groups is shown in Fig. 2 (B, D and F respectively). The skins of the naïve mice were smooth and soft (Fig. 2A). The skins of the mice in the AEW group were rough and sclerotic (Fig. 2C). The skins of the DCP-treated mice manifested congestion and sclerosis, accompanied with scratches and incrustation (Fig. 2E). There was apparent epidermal hyperplasia in the AEW and DCP groups compared with the naïve control group, as shown in Fig. $2 \mathrm{G}$ (AEW vs. naïve, $\mathrm{P}<0.05$; $\mathrm{DCP}$ vs. naïve, $\mathrm{P}<0.001$ ). 


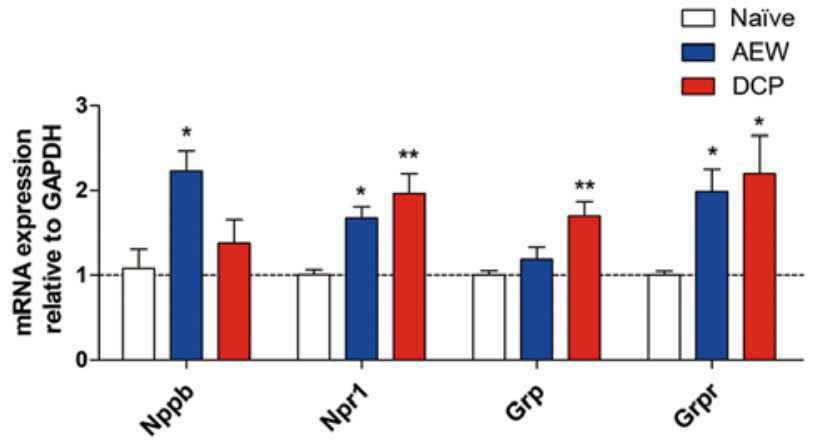

Figure 3. The mRNA levels of Nppb, Npr1, Grp and Grpr in the lower cervical spinal cord (C5-8) in the 3 groups. The gene expression levels of Nppb and Grp were significantly increased in the mice with AEW- and DCP-induced chronic itch, respectively. The mRNA expression levels of their receptors, Nprl and Grpr, were increased in both groups of chronic itch. Each value represents the mean \pm SEM of 3 independent experiments $(n=5-7$ mice per group). ${ }^{*} \mathrm{P}<0.05$ and ${ }^{* *} \mathrm{P}<0.01$ vs. naïve mice. AEW, acetone/ether/water; DCP, diphenylcyclopropenone.

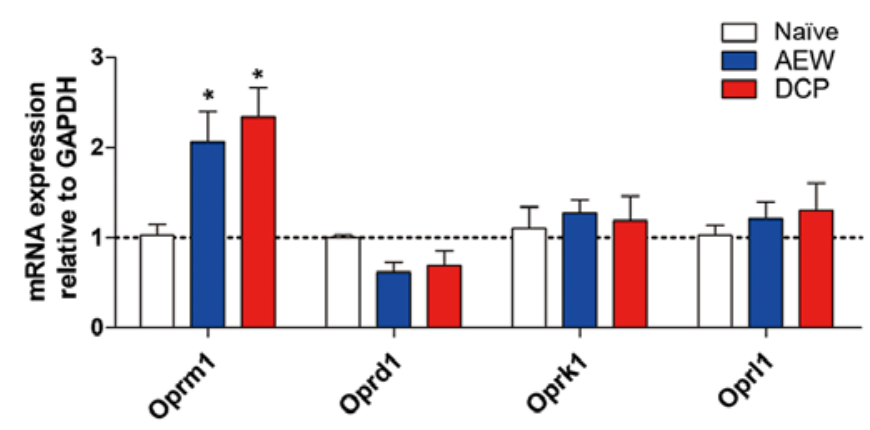

Figure 4. The mRNA level of four opioid receptors in the lower cervical spinal cord (C5-8) in three groups. The gene expression of oprm1 had a prominent elevation and other opioid receptors, such as Oprd1, Oprk1 and Oprll exhibited no significant difference in the AEW and DCP group. Each value represents mean \pm SEM of three independent experiments $(n=6-8$ mice per group). ${ }^{*} \mathrm{P}<0.05$ vs. naïve mice. $\mathrm{AEW}$, acetone/ether/water; $\mathrm{DCP}$, diphenylcyclopropenone.

mRNA expression of representative itch markers in $A E W$ group and DCP group. The mRNA expression of natriuretic peptide $\mathrm{B}(\mathrm{Nppb})$ was upregulated in the AEW group, and that of gastrin releasing peptide (Grp) was upregulated in the DCP group. Additionally, the mRNA expression levels of their receptors, Nprl and Grpr, were increased in both chronic itch groups (Fig. 3).

Oprml gene expression is increased in the AEW group and DCP group. The fold change of opioid receptor mu 1 (Oprm1) in the lower cervical spinal cord (C5-8) was increased in both the AEW and DCP groups compared with the naïve mice $(\mathrm{P}<0.05)$. The gene expression of other opioid receptors, such as opioid receptor kappa 1 (Oprk1), opioid receptor delta 1 (Oprd1) and opioid related nociceptin receptor 1 (Oprl1) exhibited no significant difference in the AEW or DCP groups compared with the naïve mice (Fig. 4).

Differential expression profiles of 5-hydroxytryptamine receptors (Htrs) in the AEW and DCP groups. The fold changes of all Htrs in the two models of different types of chronic itch compared with the naïve control mice are presented in Fig. 5. There was a significant increase in the expression levels of Htrla $(\mathrm{P}<0.01)$, Htr1d $(\mathrm{P}<0.01)$, Htr2a $(\mathrm{P}<0.01), \operatorname{Htr} 4(\mathrm{P}<0.05), H \operatorname{Ht} 5 \mathrm{a}(\mathrm{P}<0.05), \operatorname{Htr} 5 \mathrm{~b}(\mathrm{P}<0.05)$ and Htr6 $(\mathrm{P}<0.05)$ in the AEW group, whereas there was a significant increase in the expression levels of Htrla $(\mathrm{P}<0.001)$, Htr2c $(\mathrm{P}<0.05)$ and Htr6 $(\mathrm{P}<0.05)$ in the DCP group. The Htrla and Htr6 expression levels were increased in both groups. Only Htrld expression was significantly decreased in the DCP group $(\mathrm{P}<0.05$; Fig. 5).

mRNA expression of neuronal and microglial markers in the $A E W$ and DCP groups. In order to determine whether neurons and glia are activated in the spinal cords of mice with chronic itch, the mRNA expression levels of neuronal marker microtubule-associated protein 2 (Map2), astrocytic marker glial fibrillary acidic protein (Gfap) and the expression of the microglial marker ionized calcium binding adaptor molecule 1 (Iba1) were evaluated by RT-qPCR. The fold change of Map2 exhibited elevated an upregulation in the AEW group $(\mathrm{P}<0.01)$. The expression of Ibal $(\mathrm{P}<0.001)$ was significantly upregulated in the DCP group compared with the naïve mice. The mRNA expression of Gfap did not exhibit an obvious change in either model of chronic itch (Fig. 6).

Expression profile of chemokine ligands between AEW group and DCP group. In both models of chronic itch, the mRNA expression levels of $\mathrm{C}-\mathrm{C}$ motif chemokine ligand $(\mathrm{Ccl}) 2, \mathrm{Ccl} 3$, $\mathrm{Ccl} 4$ and $\mathrm{Ccl} 22$ were downregulated, whereas those of $\mathrm{Ccl} 5$, $\mathrm{Ccl} 8, \mathrm{Ccl} 21, \mathrm{Cxcl} 3$ and $\mathrm{Cxcl} 16$ were upregulated in the lower cervical spinal cord. We did not detect any gene expression of $\mathrm{Ccl} 7, \mathrm{Ccl} 25$ and $\mathrm{Ccl} 28$ within 40 cycles. Additionally, the mRNA expression of Ccll was decreased, whereas the expression levels of Ccl11 and Ccl12 were increased in the AEW group. In addition, in the DCP group, the mRNA expression levels of Ccl6, Ccl19, Ccl20, Xcl1, Cxcl1, Cxcl2, Cxcl10, Cxcl12, Cxcl14 and Cxcl15 were upregulated (Fig. 7).

Expression profiles of chemokine receptors in two models of different types of chronic itch induced by AEW and DCP. The gene expression levels of Ccr4, Ccr7, Cxcr2, Cxcr4 and Cxcr6 were increased in both chronic itch groups. The fold change of Ccr3 in the AEW group, and that of Ccr1, Ccr6, Ccr9 and Cxcr1 in the DCP group was significantly increased (Fig. 8). The detailed association of chemokine ligands and chemokine receptors is shown in Fig. 9.

\section{Discussion}

Itch and pain closely share mechanisms in neural pathways and are mediated by similar neuronal cell types and molecules. The current knowledge on itch has arisen from the investigation of pain $(1,8,9)$. Thus, valuable information on pain mediators aids our understanding of the underlying mechanisms of itch. Chronic itch is induced by peripheral neuropathy, nerve irritation, central hypersensitivity, or immune dysfunction, which can lead to itch hypersensitivity by releasing inflammatory mediators such as proinflammatory cytokines, growth factors and chemokines to activate or sensitize peripheral and central nervous systems (37). Therefore, we aimed to screen and 


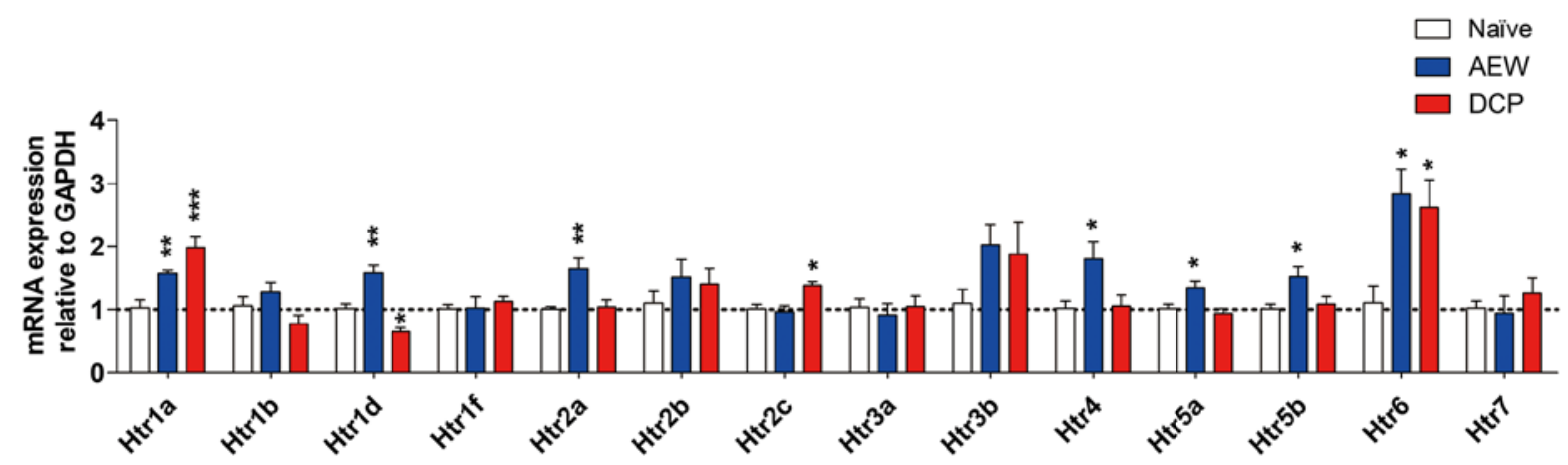

Figure 5. Gene expression profiles of Htr in the lower cervical spinal cord in the 3 groups. The mRNA levels of Htrla, Htrld, Htr2a, Htr4 and Htr6 in the mice with AEW-induced chronic itch were markedly increased, while those of Htrla, Htr2c and Htr6 were increased in the mice with DCP-induced chronic itch. The gene expression of Htrld was decreased in the model of DCP-induced chronic itch. Each value represents the mean \pm SEM of 3 independent experiments ( $\mathrm{n}=6-8$ mice per group). ${ }^{*} \mathrm{P}<0.05,{ }^{* *} \mathrm{P}<0.01$ and ${ }^{* * *} \mathrm{P}<0.001$ vs. naïve mice. AEW, acetone/ether/water; DCP, diphenylcyclopropenone; Htr, 5-hydroxytryptamine receptor.

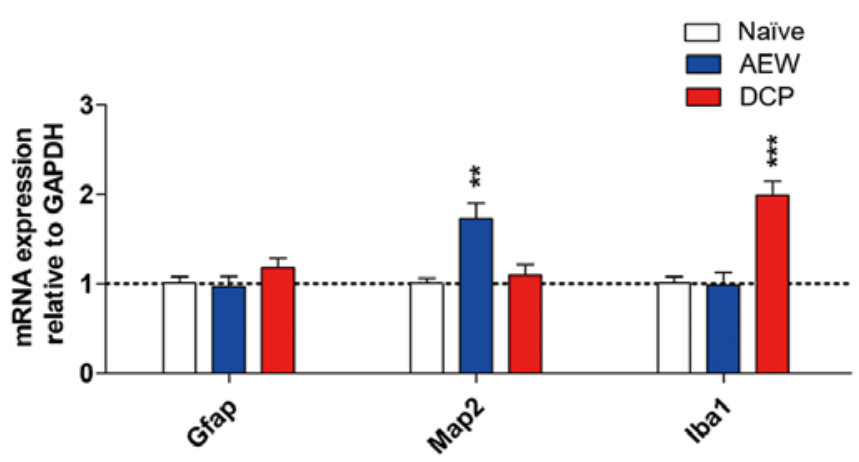

Figure 6. The mRNA levels of astrocytic, microglial and neuronal markers in the lower cervical spinal cord (C5-8) in the 3 groups. The gene expression levels of Map2 and Iba1 were significantly increased in the mice with AEW- and DCP-induced chronic itch, respectively. Each value represents the mean \pm SEM of 3 independent experiments ( $n=6-8$ mice per group) ${ }^{* *} \mathrm{P}<0.01$ and ${ }^{* * * *} \mathrm{P}<0.001$ vs. naïve mice. $\mathrm{AEW}$, acetone/ether/water; DCP, diphenylcyclopropenone.

discover critical and specific molecules or mediators in the spinal cord during chronic itch conditions.

Acting as a local irritant, DCP induces local sensitization and immune response (36). In contrast to DCP-induced contact dermatitis, AEW induces dry skin $(32,35)$. Skin dryness is one of the most common symptoms of chronic itch conditions; for example, atopic dermatitis, uremic pruritus and cholestatic pruritus (43). B-type natriuretic peptide (BNP) and natriuretic peptide receptor A (NPRA), which are encoded by the Nppb and Nprl genes, have been defined as itch-selective neuropeptides and receptors (44-46). The GRP/GRPR system has been reported to include the first-known itch-specific molecules (7). There has been controversy surrounding the expression of GRP in peripheral nerves $(45,47)$. However, GRP and its receptor, GRPR, are highly expressed in the spinal cord. GRP and GRPR expression levels are increased in the skin and spinal cord of primates exhibiting chronic itch symptoms (48). In this study, after the models of chronic itch were established, we examined the mRNA levels of most representative itch markers, such as Nppb, Nprl, Grp and Grpr in the spinal cords of AEW- and DCP-treated mice. We found that the mRNA expression levels of $\mathrm{Nppb}$ and $\mathrm{Nprl}$ were increased in the mice with AEW-induced itch. In addition, our results revealed that the mRNA expression levels of Grp and Grpr were increased in the spinal cords of mice with DCP-induced chronic itch. A previous study by Miyamoto et al demonstrated that inflammatory cells did not infiltrate the dermis of dry-skin samples from AEW-treated mice, suggesting that skin inflammation involves different mechanisms in contact dermatitis compared with dry-skin pruritus (32). Therefore, the differential expression in two types of chronic itch model suggests that the NPPB/NPR1 system plays a major role in chronic dry skin-associated pruritus, while the GRP/GRPR system is more related to chronic pruritus caused by contact dermatitis. Taken together, we identified herein that the application of AEW and DCP produces profound scratching behaviors and chronic itch in mice, as also previously described $(32,36,49)$.

In this study, most genes that we screened which appeared to be associated with itch behavior have been verified. Previously, the intrathecal application or microinjection of the agonist of KOP, DOP and NOP did not elicit obvious scratching in monkeys (50-52). However, MOP is required for intrathecal morphine-induced itch, and MOP antagonist blocks intrathecal morphine-induced itch (11). Miyamoto et al demonstrated that the subcutaneous injection of naloxone and naltrexone, which are antagonists of MOP, suppressed spontaneous scratching in AEW-treated mice, suggesting that MOP may be involved in the development of AEW-induced itch condition (32). Likewise, the results of this study demonstrated that Oprm1 expression increased in both types of models of chronic itch. Combining previous findings and our results, it can be inferred that Oprm1 plays an important role in itch mechanisms and other opioid receptor subtypes may not be involved in AEW- and DCP-induced chronic itch. According to pharmacological studies, the 5-HT1 and 5-HT2 receptors are involved in itch perception $(53,54)$. Consistent with these findings, our results further confirmed that the gene expression levels of Htrla, Htrld, Htr2a and Htr2c were upregulated in the AEW- or DCP-induced chronic itch condition. In addition, a study conducted by Tian et al identified that the mRNA expression levels of Htrld, Htr2a, Htr2c, Htr5a, Htr5b and Htr6 were increased in the trigeminal ganglia and dorsal root ganglia of rats exhibiting cholestatic itch (55). Furthermore, the study by Morita et al demonstrated that 5-HT7 was a key mediator of 

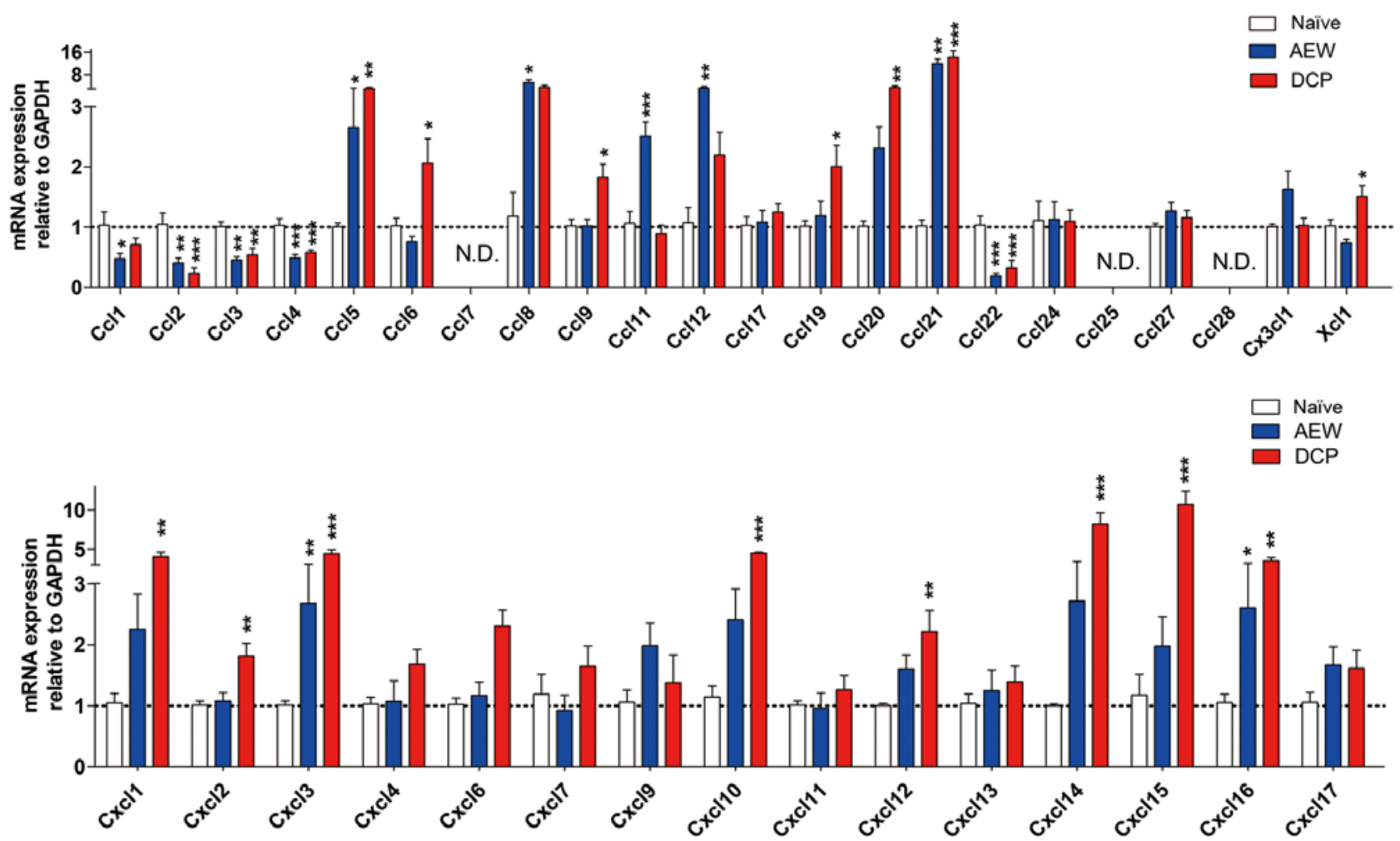

Figure 7. The mRNA expression levels of chemokine ligands in the lower cervical spinal cord in the 3 groups. Fold changes of chemokine ligands mRNA expression levels in the mice with AEW-induced chronic itch and in mice with DCP-induced chronic itch as compared with the naïve mice are shown. N.D. indicates that there was no gene expression detected. Each value represents the mean \pm SEM of 3 independent experiments ( $\mathrm{n}=6-8$ mice per group). "P<0.05, ${ }^{* *} \mathrm{P}<0.01$ and ${ }^{* * *} \mathrm{P}<0.001$ vs. naïve mice. AEW, acetone/ether/water; DCP, diphenylcyclopropenone.

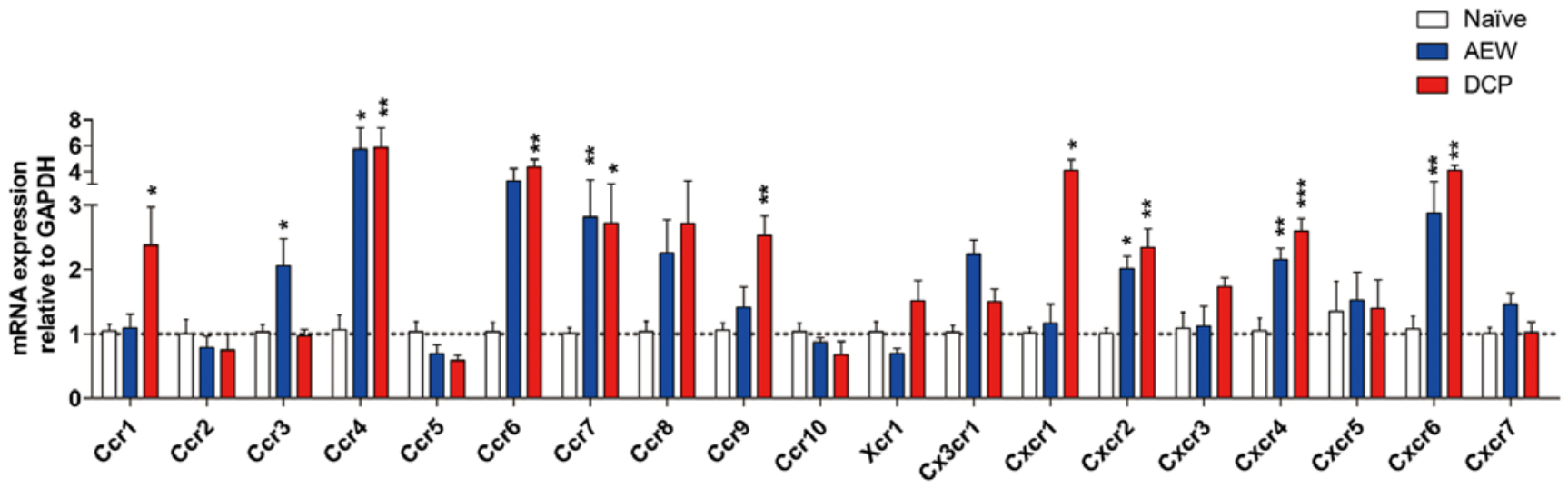

Figure 8. The mRNA level of chemokine receptors in the lower cervical spinal cord (C5-8) in the 3 groups. Fold changes of Ccr4, Ccr7, Cxcr2, Cxcr4 and Cxcr6 mRNA levels were significantly increased in both models of chronic itch compared with the naïve group. Gene expression levels of Ccr3 in the AEW group, and those of Ccr1, Ccr6, Ccr9 and Cxcr1 in the DCP group were significantly increased. Each value represents the mean \pm SEM of 3 independent experiments ( $\mathrm{n}=6-8$ mice per group). ${ }^{*} \mathrm{P}<0.05,{ }^{* *} \mathrm{P}<0.01$ and ${ }^{* * *} \mathrm{P}<0.001$ vs. naïve mice. AEW, acetone/ether/water; $\mathrm{DCP}$, diphenylcyclopropenone.

acute serotonergic itch and chronic atopic dermatitis itch (56). However, a recent study confirmed the role of Htr2a, but not $\mathrm{Htr} 7$, in allergic contact dermatitis itch and of $\mathrm{Htr} 7$, but not Htr2a, in dry skin-associated chronic itch (57). Although these two studies both used knockout mice to verify the roles of 5-HT receptors, residual pruritus behaviors in animals lacking $\mathrm{Htr} 7$ or Htr2a have still been observed, suggesting that other 5-HT receptors or molecules are required for the development of chronic itch models. In this study, the increased mRNA level of Htr2a in the spinal cord was preliminarily screened.
Whether Htr2a is involved in dry skin itch requires further verification. Although the exact subtypes of 5-HT receptors involved in different mouse models of chronic itch have yet to be elucidated, these studies and our results highlight the crucial roles of serotonergic signaling in chronic itch pathology. In brief, we found that the gene expression levels of Htrla, Htr6 and Oprm1 were upregulated in both models of chronic itch.

In order to determine whether neurons and glia were activated in the spinal cord of mice with chronic itch, we examined neuronal and microglial marker expression between 


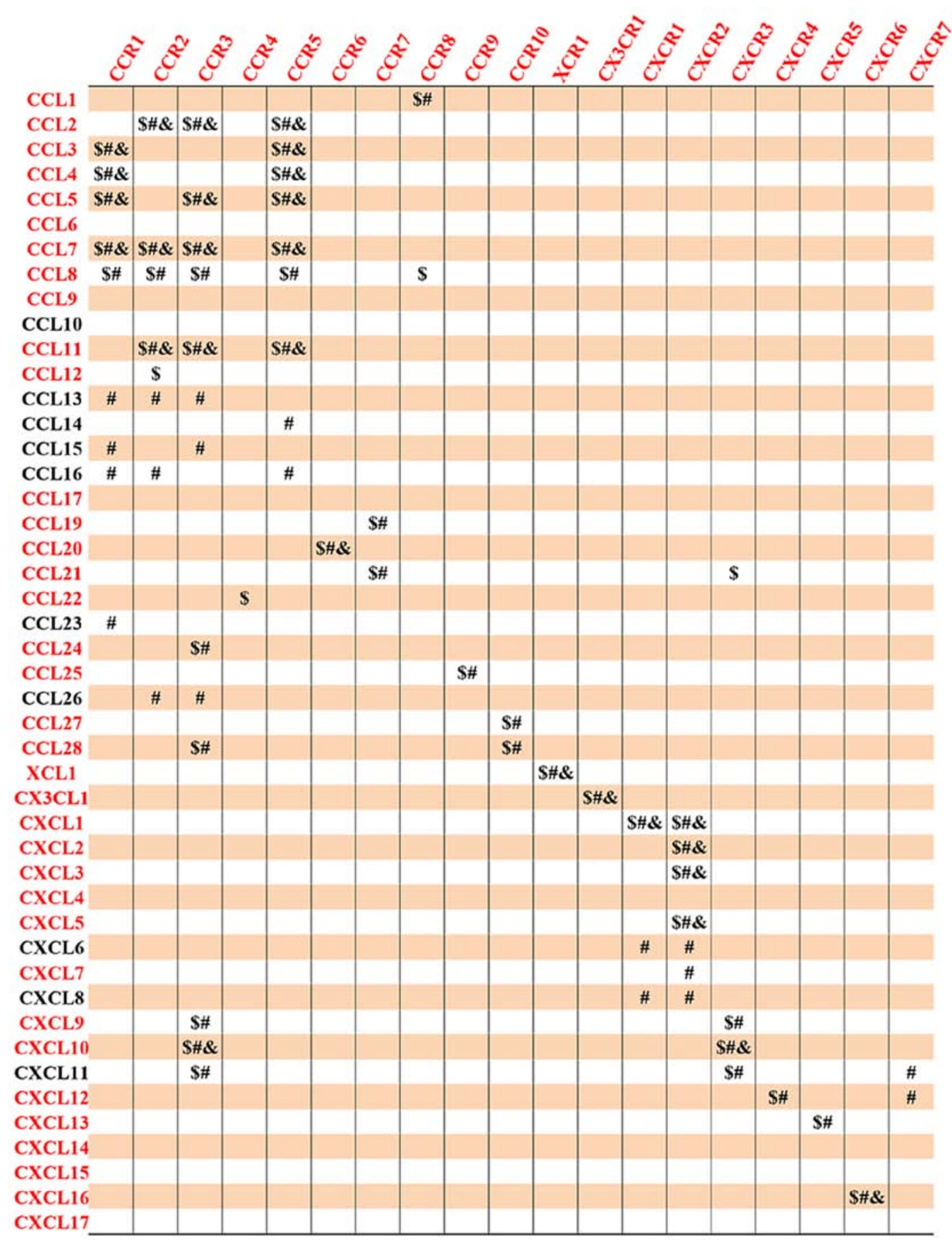

Figure 9. The chemokine receptor-ligand network. The horizontal line represents chemokine receptors and the vertical line represents chemokine ligands. ${ }^{\$}$ Represents mouse chemokine ligands in the vertical column binding to the receptors in the horizontal row. "Indicates human chemokine ligands in the vertical column binding to the receptors in the horizontal row. ${ }^{\&}$ Indicates rat chemokine ligands in the vertical column binding to the receptors in the horizontal row. For more detailed information, visit the website of The International Union of Basic and Clinical Pharmacology (IUPHAR) (https://iuphar.org/). The chemokines in red are referenced in this study.

the AEW and DCP groups. Previously, Liu et al employed pharmacological and transgenic approaches to verify that AEW could induce the activation of astrocytes in the spinal cord of mice. Interestingly, they also found that spinal astrogliosis was affected by scratching behavior, which was abrogated when mice were prevented from scratching pruritus skin by Elizabethan Collars (49). This novel finding was consistent with that in the study by Wilson et al, in which the extent of keratinocyte hyperplasia in the skin of AEW mice was found to be scratch-dependent (58). By contrast, in this study, we found that the expression level of Map2, which is a neuronal marker, was much higher than that of Gfap in the spinal cords of AEW-induced itch mice. A recent study highlighted the importance of Map2 in controlling the axonal entry of cargo vesicles and regulating their distribution along the distal axon. It suggested that Map2 controls axonal cargo transport and drives synaptic and secretory vesicle accumulation in the periphery (59). Therefore, the increase in the expression of Map2 in the AEW group may be attributed to the increased secretory vesicle in neurons. In 
addition, Map2 has been reported to play an important role in neuronal morphogenesis and to affect microtubule density and the length of dendrites (60). The increased expression of Map2 may enhance the sprouting and synaptic plasticity of dendrites, resulting in neural hypersensitivity. Therefore, in long-term skin dryness, pathological changes of the central nervous system, such as neuropathic itch may occur and lead to Map2 upregulation, which enhances the sprouting and synaptic plasticity of dendrites. Another explanation is that the expression of Map2 is not restricted to neurons. For instance, it has been reported before that reactive astrocytes may express neuron-specific enolase and Map2 $(61,62)$. We also found the expression level of Iba1, which is a microglial marker, was prominently increased in the spinal cords of mice with DCP-induced chronic itch. It has been established that the mediation of gene expression varies over time (63-66). The main difference between the two studies is that Liu et al examined expression levels in the cervical dorsal horn 5 days after AEW treatment while we examined the cervical spinal cord 9 after treatment. In long-term skin dryness, pathological changes of the central nervous system, such as neuropathic itch may occur and can lead to the upregulation of Map2, which enhances the sprouting and synaptic plasticity of dendrites.

Over the past decade, a dermatology study demonstrated the expression patterns of chemokines in the skin of a chronic proliferative dermatitis mutant mouse model, which was a useful way of investigating the role of chemokines in eosinophil accumulation in chronic inflammation (67). Chemokine ligands and receptors, which participate in the induction and maintenance of inflammation, have been studied in several diseases models as inflammatory mediators. Although chemokines and their receptors have been implicated in the pathophysiology of chronic pain, they have been largely unexplored in chronic itch conditions. Among the chemokines examined in this study, the mRNA expression levels of $\mathrm{Ccl} 2$, $\mathrm{Ccl} 3, \mathrm{Ccl} 4$ and $\mathrm{Ccl} 22$ were downregulated in the two mouse models of chronic itch. Another study observed the conspicuously decreased serum concentration of CCL2, CCL3, CCL4 and CCL5 by an enzyme-linked immunosorbent assay in the ragweed-allergic patients out of the pollen season. It seemed that the allergic subjects protected against the initiation of an allergic inflammatory reaction by maintaining a low physiologic concentration of chemokines (68). Thus, the decrease in the levels of these chemokines may be a mechanism through which tissues can be protected from damage by continuously recruiting cascaded immune mediators to the lesion sites. Consistent with our findings of the upregulation of $\mathrm{Ccl} 21$ and Ibal in DCP-induced itch, Biber et al identified that neuronal $\mathrm{Ccl} 21$ upregulated the expression of ionotropic purinoceptors P2X4 in spinal cord microglia (69). The release of Ccl21, which is a potent microglial activator, was markedly increased after neural hyperexcitability or injury (70). In our study, the mRNA levels of $\mathrm{Ccl} 21$ were dramatically upregulated in two different chronic itch models, suggesting that the activation of microglia cells may be triggered by $\mathrm{Ccl} 21$. Therefore, $\mathrm{Ccl} 21$ may be a promising drug target in chronic itch intervention. A recent study by Jing et al investigated whether spinal cord chemokines could contribute to the development of chronic itch. They reported that $\mathrm{Cxcr} 3$-deficiency mice showed reduced scratching in chronic itch models induced by AEW, DCP and 2,4-dinitro-1-fluorobenzene (DNFB). Moreover, their results revealed the mRNA and protein expression levels of CXCR3 and CXCL10 in the spinal cord 7 days after AEW treatment increased significantly, suggesting that spinal cord chemokines may be involved in the alteration of skin induced by itch mediators (71). We found that the mRNA level of Cxcl10 was similarly up-regulated in DCP-induced contact dermatitis in our results. However, we did not detect significant alteration of Cxcl10 or Cxcr3 in AEW-induced dry-skin itch. Their results showed that SSB in the group of wild-type mice treated with AEW at day 7 reached over 350 within $1 \mathrm{~h}$. Our data demonstrated that SSB reached 155.5 by day 9 . As mentioned, scratching behaviors can affect glial activation of spinal cord in AEW mice $(49,58)$. This difference may be the result from methodological differences in model construction. The up-regulation of CXCL12-CXCR4 chemokine ligand-receptor systems has been reported in the thalamus of diabetic monkeys accompanied with neuroinflammation (23). The results of this study demonstrated that the mRNA levels of both Cxcl12 and Cxcr4 were upregulated in the DCP-treated mice. In addition, our results revealed that some chemokines along with their receptors were upregulated in two types of chronic itch mice, Ccl21-Ccr7, Cxcl3-Cxcr2 and Cxcl16-Cxcr6, suggesting that these ligand-receptor systems may play an important role in chronic itch development. However, the actual role of these signaling pathways must be verified in further research. In summary, it seems that some of these related genes in the spinal cord may be involved in the mediation of skin inflammation in chronic itch conditions. In particular, the activation of glial cells is vital for the development of chronic itch, suggesting that maintaining a balance of chemokines in the spinal cord may provide a new direction for therapeutic development. The details of the association between chemokine ligands and chemokine receptors are shown in Fig. 9.

This study documents the profiles of several itch mediators in two types of chronic itch. Moreover, we observed that the levels of several chemokine ligands and their receptors were simultaneously upregulated in both dry-skin and contact dermatitis chronic itch. Nevertheless, there are some limitations to our research. The exact role of the differentially expressed genes in chronic itch warrants further investigation in future studies. The changes in mRNA levels may not always reflect the changes in protein levels, since many factors influence the expression of proteins. For instance, the processes regulated protein expression between transcription and translation could be affected at many different stages and many different ways. In addition, following translation, protein expression can also be regulated post-translational modifications. However, the transcription level data can suggest whether the protein is present or not and roughly what at level to expect to find the protein. For example, a highly abundant protein will usually have a highly expressed mRNA. The transcription data is useful for identifying potential candidates for follow-up work at the protein level. The goal of this study was to draw out the gene expression patterns of itch-related mediators in chronic itch model. To a certain extent, it was a way to narrow the range and select the candidate mediators for further investigating mechanisms of chronic itch. Western blot analysis may be use in any future study by our group to confirm the results of the present study. In conclusion, the data 
of this study identify several molecular determinants of itch in the spinal cord and provides a useful baseline in gene level for functional experimentation or crosstalk between these related mediators. Our research may thus contribute to future research on endogenous triggers of chronic itch signaling, which may provide significant breakthroughs for the treatment of obstinate pruritus.

\section{Acknowledgements}

Not applicable.

\section{Funding}

This study was supported by grants from National Natural Science Foundation of P.R. China (Nos. 81670240, 81271766 and 81674057), the National Natural Science Foundation of Hubei Province (Nos. 2016CFB625 and 2016CFB324) and the Special Fund of Fundamental Scientific Research Business Expense for Higher School of Central Government (2012 TS060 to HBX).

\section{Availability of data and materials}

All data generated or analyzed during this study are included in this published article.

\section{Authors' contributions}

BWL performed the RT-qPCR experiments, analyzed the data and wrote the manuscript. ZXL and ZGH established the itch models and collected tissues, QW and CL performed the histology experiments. XWZ, HY and HBX contributed to the study concept and design, and supervised the project. All authors have read and approved the manuscript.

\section{Ethics approval and consent to participate}

This study was performed following the approval of the Institutional Ethical Committee of Tongji Hospital, Tongji Medical College, Huazhong University of Science and Technology (no. TJ-A20150803).

\section{Patient consent for publication}

Not applicable.

\section{Competing interests}

The authors declare that they have no competing interests.

\section{References}

1. Ikoma A, Steinhoff M, Stander S, Yosipovitch G and Schmelz M The neurobiology of itch. Nat Rev Neurosci 7: 535-547, 2006.

2. He ZG, Liu BW, Li ZX, Liu C, Liu C and Xiang HB: Altered expression profiling of spinal genes modulated by compound 48/80 in a mouse itch model. J Anesth Perioper Med 4: 220-224, 2017.

3. Chen M, Li ZX, Wang Q and Xiang HB: Altered expression of differential genes in thoracic spinal cord involved in experimental cholestatic itch mouse model. Curr Med Sci 38: 679-683, 2018.
4. Ding DF, Li RC, Xiong QJ, Zhou L and Xiang HB: Pulsed radiofrequency to the great occipital nerve for the treatment of intractable postherpetic itch: A case report. Int J Clin Exp Med 7: 3497-3500, 2014

5. Liu BW, Li ZX, He ZG, Liu C, Xiong J and Xiang HB: Altered expression of target genes of spinal cord in different itch models compared with capsaicin assessed by RT-qPCR validation. Oncotarget 8: 74423-74433, 2017.

6. Bernhard JD: Itch and pruritus: What are they, and how should itches be classified? Dermatol Ther 18: 288-291, 2005.

7. Sun YG and Chen ZF: A gastrin-releasing peptide receptor mediates the itch sensation in the spinal cord. Nature 448: 700-703, 2007.

8. Ikoma A, Rukwied R, Stander S, Steinhoff M, Miyachi Y and Schmelz M: Neurophysiology of pruritus: Interaction of itch and pain. Arch Dermatol 139: 1475-1478, 2003.

9. Moser HR and Giesler GJ Jr: Itch and analgesia resulting from intrathecal application of morphine: Contrasting effects on different populations of trigeminothalamic tract neurons. J Neurosci 33: 6093-6101, 2013.

10. Akiyama $T$ and Carstens E: Neural processing of itch. Neuroscience 250: 697-714, 2013.

11. Ko MC: Neuraxial opioid-induced itch and its pharmacological antagonism. Handb Exp Pharmacol 226: 315-335, 2015.

12. Ahmadi S, Karami Z, Mohammadian A, Khosrobakhsh F and Rostamzadeh J: Cholestasis induced antinociception and decreased gene expression of MOR1 in rat brain. Neuroscience 284: 78-86, 2015.

13. Liu C, Liu TT, He ZG, Shu B and Xiang HB: Inhibition of itch-related responses by selectively ablated serotonergic signals at the rostral ventromedial medulla in mice. Int J Clin Exp Pathol 7: 8917-8921, 2014.

14. Li HJ, Johnston B, Aiello D, Caffrey DR, Giel-Moloney M, Rindi $G$ and Leiter AB: Distinct cellular origins for serotonin-expressing and enterochromaffin-like cells in the gastric corpus. Gastroenterology 146: 754-764, 2014.

15. Hoon MA: Molecular dissection of itch. Curr Opin Neurobiol 34: 61-66, 2015.

16. Liu T, He Z, Tian X, Kamal GM, Li Z, Liu Z, Liu H, Xu F, Wang J and Xiang H: Specific patterns of spinal metabolites underlying alpha-Me-5-HT-evoked pruritus compared with histamine and capsaicin assessed by proton nuclear magnetic resonance spectroscopy. Biochim Biophys Acta Mol Basis Dis 1863: 1222-1230, 2017.

17. Berger M, Gray JA and Roth BL: The expanded biology of serotonin. Annu Rev Med 60: 355-366, 2009.

18. Beattie DT and Smith JA: Serotonin pharmacology in the gastrointestinal tract: A review. Naunyn Schmiedebergs Arch Pharmacol 377: 181-203, 2008.

19. Steinhoff M, Cevikbas F, Ikoma A and Berger TG: Pruritus: Management algorithms and experimental therapies. Semin Cutan Med Surg 30: 127-137, 2011.

20. Ji RR, Xu ZZ and Gao YJ: Emerging targets in neuroinflammation-driven chronic pain. Nat Rev Drug Discov 13: 533-548, 2014.

21. Kawasaki Y, Zhang L, Cheng JK and Ji RR: Cytokine mechanisms of central sensitization: Distinct and overlapping role of interleukin-1beta, interleukin-6, and tumor necrosis factor-alpha in regulating synaptic and neuronal activity in the superficial spinal cord. J Neurosci 28: 5189-5194, 2008.

22. Tsuda M, Shigemoto-Mogami Y, Koizumi S, Mizokoshi A, Kohsaka S, Salter MW and Inoue K: P2X4 receptors induced in spinal microglia gate tactile allodynia after nerve injury. Nature 424: 778-783, 2003.

23. Kiguchi N, Ding H, Peters CM, Kock ND, Kishioka S, Cline JM, Wagner JD and Ko MC: Altered expression of glial markers, chemokines, and opioid receptors in the spinal cord of type 2 diabetic monkeys. Biochim Biophys Acta Mol Basis Dis 1863: 274-283, 2017.

24. Shiratori-Hayashi M, Koga K, Tozaki-Saitoh H, Kohro Y, Toyonaga H, Yamaguchi C, Hasegawa A, Nakahara T, Hachisuka J, Akira S, et al: STAT3-dependent reactive astrogliosis in the spinal dorsal horn underlies chronic itch. Nat Med 21: 927-931, 2015.

25. Zlotnik A and Yoshie O: The chemokine superfamily revisited. Immunity 36: 705-716, 2012.

26. Melik-Parsadaniantz S and Rostene W: Chemokines and neuromodulation. J Neuroimmunol 198: 62-68, 2008.

27. White FA, Jung $\mathrm{H}$ and Miller RJ: Chemokines and the pathophysiology of neuropathic pain. Proc Natl Acad Sci USA 104: 20151-20158, 2007. 
28. Gao YJ and Ji RR: Chemokines, neuronal-glial interactions, and central processing of neuropathic pain. Pharmacol Ther 126: $56-68,2010$

29. Charo IF and Ransohoff RM: The many roles of chemokines and chemokine receptors in inflammation. N Engl J Med 354: $610-621,2006$

30. Asensio VC and Campbell IL: Chemokines in the CNS Plurifunctional mediators in diverse states. Trends Neurosci 22: 504-512, 1999.

31. Savarin-Vuaillat C and Ransohoff RM: Chemokines and chemokine receptors in neurological disease: Raise, retain, or reduce? Neurotherapeutics 4: 590-601, 2007.

32. Miyamoto T, Nojima H, Shinkado T, Nakahashi T and Kuraishi Y: Itch-associated response induced by experimental dry skin in mice. Jpn J Pharmacol 88: 285-292, 2002.

33. Thaipisuttikul Y: Pruritic skin diseases in the elderly. J Dermatol 25: 153-157, 1998.

34. Di Nardo A, Wertz P, Giannetti A and Seidenari S: Ceramide and cholesterol composition of the skin of patients with atopic dermatitis. Acta Derm Venereol 78: 27-30, 1998.

35. Sun YG, Zhao ZQ, Meng XL, Yin J, Liu XY and Chen ZF: Cellular basis of itch sensation. Science 325: 1531-1534, 2009.

36. Zhang TT, Shen FY, Ma LQ, Wen W, Wang B, Peng YZ, Wang ZR and Zhao X: Potentiation of synaptic transmission in Rat anterior cingulate cortex by chronic itch. Mol Brain 9: 73, 2016.

37. Ji RR: Neuroimmune interactions in itch: Do chronic itch, chronic pain, and chronic cough share similar mechanisms? Pulm Pharmacol Ther 35: 81-86, 2015.

38. Valtcheva MV, Samineni VK, Golden JP, Gereau RW IV and Davidson S: Enhanced nonpeptidergic intraepidermal fiber density and an expanded subset of chloroquine-responsive trigeminal neurons in a mouse model of dry skin itch. J Pain 16 346-356, 2015

39. Geng X, Shi H, Ye F, Du H, Qian L, Gu L, Wu G, Zhu C, Yang Y, Wang C, et al: Matrine inhibits itching by lowering the activity of calcium channel. Sci Rep 8: 11328, 2018

40. Liu Y, Liu J, Li M, Dai S, Liang J and Ji W: The effect of kinin B1 receptor on chronic itching sensitization. Mol Pain 11: 70, 2015.

41. Xu Y, Zhang XH and Pang YZ: Association of tyrosinase (TYR) and tyrosinase-related protein 1 (TYRP1) with melanic plumage color in korean quails (Coturnix coturnix). Asian-Australas J Anim Sci 26: 1518-1522, 2013.

42. Schmittgen TD and Livak KJ: Analyzing real-time PCR data by the comparative C(T) method. Nature Protoc 3: 1101-1108, 2008

43. Han L and Dong X: Itch mechanisms and circuits. Annu Rev Biophys 43: 331-355, 2014.

44. Shimizu Y, Sonoda A, Nogi C, Ogushi Y, Kanda R, Yamaguchi S, Nohara N, Aoki T, Yamada K, Nakata J, et al: B-type (brain) natriuretic peptide and pruritus in hemodialysis patients. Int J Nephrol Renovasc Dis 7: 329-335, 2014.

45. Mishra SK and Hoon MA: The cells and circuitry for itch responses in mice. Science 340: 968-971, 2013

46. Kiguchi N, Sukhtankar DD, Ding H, Tanaka K, Kishioka S, Peters CM and Ko MC: Spinal functions of B-type natriuretic peptide, gastrin-releasing peptide, and their cognate receptors for regulating itch in mice. J Pharmacol Exp Ther 356: 596-603, 2016

47. Liu XY, Wan L, Huo FQ, Barry DM, Li H, Zhao ZQ and Chen ZF: B-type natriuretic peptide is neither itch-specific nor functions upstream of the GRP-GRPR signaling pathway. Mol Pain 10: 4, 2014

48. Nattkemper LA, Zhao ZQ, Nichols AJ, Papoiu ADP, Shively CA, Chen ZF and Yosipovitch G: Overexpression of the gastrin-releasing peptide in cutaneous nerve fibers and its receptor in the spinal cord in primates with chronic itch. J Invest Dermatol 133: 2489-2492, 2013

49. Liu T, Han Q, Chen G, Huang Y, Zhao LX, Berta T, Gao YJ and Ji RR: Toll-like receptor 4 contributes to chronic itch, alloknesis, and spinal astrocyte activation in male mice. Pain 157: 806-817, 2016.

50. Thomas DA, Williams GM, Iwata K, Kenshalo DR Jr and Dubner R: Effects of central administration of opioids on facial scratching in monkeys. Brain Res 585: 315-317, 1992.

51. Ko MC, Lee H, Harrison C, Clark MJ, Song HF, Naughton NN Woods JH and Traynor JR: Studies of micro-, kappa-, and delta-opioid receptor density and $G$ protein activation in the cortex and thalamus of monkeys. J Pharmacol Exp Ther 306 179-186, 2003

52. Ko MC, Wei H, Woods JH and Kennedy RT: Effects of intrathecally administered nociceptin/orphanin FQ in monkeys: Behavioral and mass spectrometric studies. J Pharmacol Exp Ther 318: 1257-1264, 2006
53. Ishiuji Y, Coghill RC, Patel TS, Dawn A, Fountain J, Oshiro Y and Yosipovitch G: Repetitive scratching and noxious heat do not inhibit histamine-induced itch in atopic dermatitis. Br J Dermatol 158: 78-83, 2008

54. Kim DK, Kim HJ, Kim H, Koh JY, Kim KM, Noh MS, Kim JJ and Lee CH: Involvement of serotonin receptors 5-HT1 and 5-HT2 in 12(S)-HPETE-induced scratching in mice. Eur J Pharmacol 579: 390-394, 2008.

55. Tian B, Wang XL, Huang Y, Chen LH, Cheng RX, Zhou FM, Guo R, Li JC and Liu T: Peripheral and spinal 5-HT receptors participate in cholestatic itch and antinociception induced by bile duct ligation in rats. Sci Rep 6: 36286, 2016.

56. Morita T, McClain SP, Batia LM, Pellegrino M, Wilson SR Kienzler MA, Lyman K, Olsen AS, Wong JF, Stucky CL, et al: HTR7 Mediates serotonergic acute and chronic itch. Neuron 87: 124-138, 2015.

57. Luo J, Feng J, Yu G, Yang P, Mack MR, Du J, Yu W, Qian A Zhang Y, Liu S, et al: Transient receptor potential vanilloid 4-expressing macrophages and keratinocytes contribute differentially to allergic and nonallergic chronic itch. J Allergy Clin Immunol 141: 608-619, 2018

58. Wilson SR, Nelson AM, Batia L, Morita T, Estandian D, Owens DM, Lumpkin EA and Bautista DM: The ion channel TRPA1 is required for chronic itch. J Neurosci 33: 9283-9294, 2013.

59. Ribeiro LF and de Wit J: Neuronal polarity: MAP2 shifts secretory vesicles into high gear for long-haul transport down the axon. Neuron 94: 223-225, 2017

60. Mohan R and John A: Microtubule-associated proteins as direct crosslinkers of actin filaments and microtubules. IUBMB Life 67: 395-403, 2015.

61. Geisert EE Jr, Johnson HG and Binder LI: Expression of microtubule-associated protein 2 by reactive astrocytes. Proc Natl Acad Sci USA 87: 3967-3971, 1990.

62. Ridet JL, Malhotra SK, Privat A and Gage FH: Reactive astrocytes: Cellular and molecular cues to biological function. Trends Neurosci 20: 570-577, 1997

63. Harrison BJ, Venkat G, Hutson T, Rau KK, Bunge MB, Mendell LM, Gage FH, Johnson RD, Hill C and Rouchka EC: Transcriptional changes in sensory ganglia associated with primary afferent axon collateral sprouting in spared dermatome model. Genom Data 6: 249-252, 2015

64. Knowlton WM, Palkar R, Lippoldt EK, McCoy DD, Baluch F, Chen J and McKemy DD: A sensory-labeled line for cold: TRPM8-expressing sensory neurons define the cellular basis for cold, cold pain, and cooling-mediated analgesia. J Neurosci 33: 2837-2848, 2013.

65. Yang W, Rudick CN, Hoxha E, Allsop SA, Dimitrakoff JD and Klumpp DJ: $\mathrm{Ca}(2+) /$ calmodulin-dependent protein kinase II is associated with pelvic pain of neurogenic cystitis. Am J Physiol Renal Physiol 303: F350-F356, 2012.

66. Ke C, Gao F, Tian X, Li C, Shi D, He W and Tian Y: Slit2/Robol mediation of synaptic plasticity contributes to bone cancer pain. Mol Neurobiol 54: 295-307, 2017.

67. Renninger ML, Seymour R, Lillard JW Jr, Sundberg JP and HogenEsch H: Increased expression of chemokines in the skin of chronic proliferative dermatitis mutant mice. Exp Dermatol 14: 906-913, 2005.

68. Kostova Z, Batsalova T, Moten D, Teneva I and Dzhambazov B: Ragweed-allergic subjects have decreased serum levels of chemokines CCL2, CCL3, CCL4 and CCL5 out of the pollen season. Cent-Eur J Immunol 40: 442-446, 2015.

69. Biber K, Tsuda M, Tozaki-Saitoh H, Tsukamoto K, Toyomitsu E, Masuda T, Boddeke H and Inoue K: Neuronal CCL21 up-regulates microglia P2X4 expression and initiates neuropathic pain development. EMBO J 30: 1864-1873, 2011.

70. Hulsebosch CE, Hains BC, Crown ED and Carlton SM: Mechanisms of chronic central neuropathic pain after spinal cord injury. Brain Res Rev 60: 202-213, 2009

71. Jing PB, Cao DL, Li SS, Zhu M, Bai XQ, Wu XB and Gao YJ: Chemokine receptor CXCR3 in the spinal cord contributes to chronic itch in mice. Neurosci Bull 34: 54-63, 2017.

This work is licensed under a Creative Commons Attribution-NonCommercial-NoDerivatives 4.0 International (CC BY-NC-ND 4.0) License. 